\title{
E-Commerce: The Next Global Frontier For Small Businesses
}

Kamlesh T. Mehta, (Email: kmehta@stmarytx.edu), St. Mary’s University, San Antonio Vivek Shah, (Email: vs01@swt.edu), Southwest Texas State University

\begin{abstract}
This paper discusses the growth of E-Commerce and its advantages to small business firms. Guidelines for small businesses to create a successful E-Commerce sites on the Internet are offered. Furthermore, tools for the trade and strategies for E-Commerce are discussed. Business on the Internet will continue to develop as technologies for the Internet evolve, and the evolution seems to be progressing at an ever-increasing pace.
\end{abstract}

Keywords: ISDL08271951 